\title{
Hochkonjunktur in der Branche
}

Unter den Maschinenbaubranchen läuft es für die Oberflächentechnik seit Jahren besonders gut. In den letzten fünf Jahren ist die Oberflächentechnik um 48 Prozent gewachsen. Für das laufende Jahr geht der VDMA von einer sehr guten Auslastung aus.

Die Fachabteilung Oberflächentechnik im VDMA hat auf einer Pressekonferenz anlässlich der Surface Technology Germany aktuelle Branchenzahlen veröffentlicht. „Die Branche befindet sich in einer Hochkonjunktur“, sagt Dr. Thomas Schräder, Geschäftsführer Allgemeine Lufttechnik im Verband Deutscher Maschinen- und Anlagenbau (VDMA). „Unser Verband hat die Wachstumsprognose für 2018 erst kürzlich auf fünf Prozent nach oben korrigiert. Aber gerade in Zeiten erhitzter Konjunktur dürfen wir die wichtigen Zukunftsthemen nicht aus den Augen verlieren. Funktionale Oberflächen sind unverzichtbare Begleiter, manchmal sogar Taktgeber für Innovationen im Maschinenbau“.

Unter den Maschinenbaubranchen läuft es für die Oberflächentechnik seit Jahren besonders gut. Für das laufende Jahr geht die VDMA Oberflächentechnik von rund 2,3 Milliarden Euro Produktionsvolumen aus. Damit ist die deutsche Oberflächentechnik in 5 Jahren um 48 Prozent gewachsen (Bild 1). Auch die Produktion des deutschen Maschinenbaus insgesamt läuft derzeit auf Hochtouren. Mit einem Produktionsvolumen von 215 Milliarden Euro in 2017 und weiteren 5 Prozent Wachstum für das laufende Jahr sind die deutschen Maschinenhersteller sehr gut ausgelastet.

\section{China und USA größte Abnehmer für deutsche Oberflächentechnik}

In der Oberflächentechnik hat China mit 17 Prozent Anteil in der Rangliste der Exportnationen inzwischen mit Deutschland gleichgezogen (Bild 2).

Der internationale Handel der Oberflächentechnik ist durch eine konzentrierte Anbieterstruktur charakterisiert. Die 7 stärksten Exportnationen stehen für drei Viertel des Marktes.
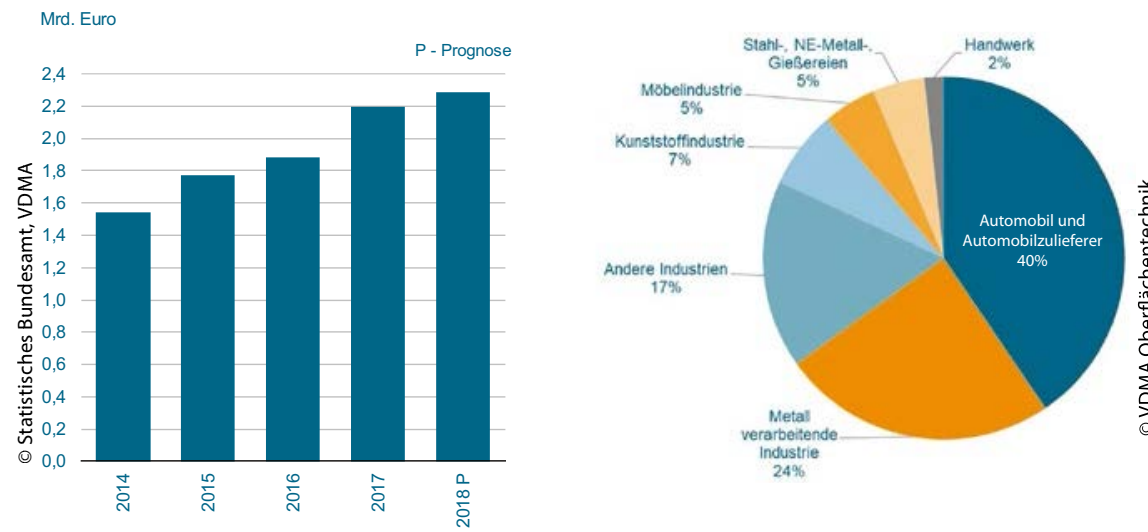

Bild 1 > Oberflächentechnik - Deutsche Produktion.

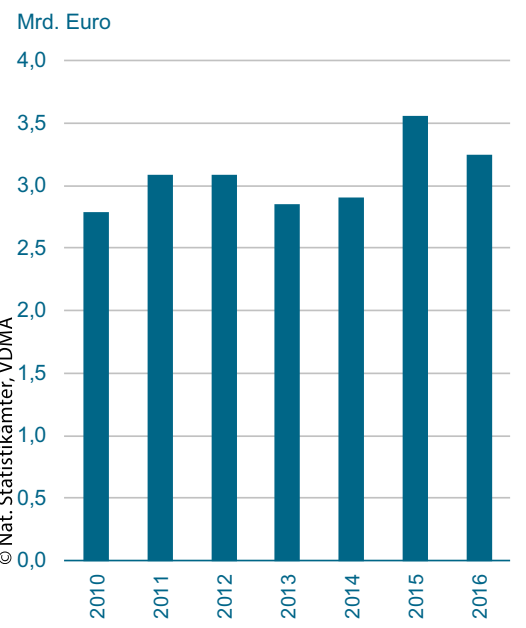

Anteile 2016

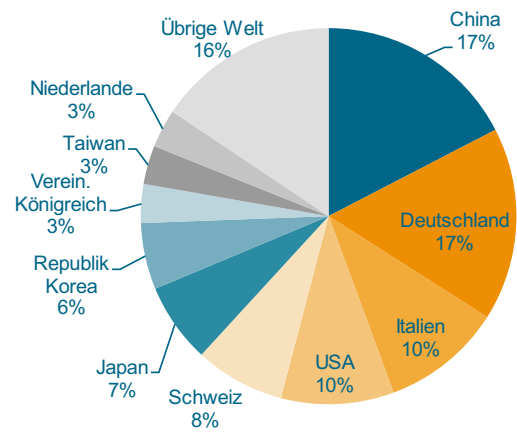

Bild 2 > Oberflächentechnik - Welthandel nach Ausfuhren.

Abnehmerseitig bleiben China und USA die stärksten Nachfragemärkte für deutsche Oberflächentechnik. Diesen beiden folgt ein europäisch dominiertes Mittelfeld. Rund zwei Drittel der deutschen Maschinenexporte der Oberflächentechnik gehen in die 13 stärksten Zielmärkte. Allerdings dominiert der europäische Binnenmarkt die Nachfrage nach deutscher Oberflächentechnik mit über 50 Prozent.

Das heterogene Technologieangebot der Oberflächentechnik umfasst zum Beispiel die Lackiertechnik, die Strahltechnik, die Reinigungs- und Vorbehandlungstechnik und die industrielle Plasma-Oberflächentechnik und wird in allen Bereichen der produzierenden Industrie genutzt. Die zusammengerechnet mit über 60 Prozent Anteil umsatzstärksten Abnehmerbranchen - die Automobilindustrie und die metallverarbeitende Industrie - stellen höchste Anforderungen an die Leistungsfähigkeit ihrer Produkte und bieten so die größten Innovationsimpulse für die Oberflächentechnik. // 